\title{
Caspases are not localized in mitochondria during life or death
}

\author{
G van Loo ${ }^{1}$, X Saelens ${ }^{1}, \mathrm{~F}$ Matthijssens ${ }^{1}$, P Schotte $^{2}$, \\ $R$ Beyaert ${ }^{2}$, W Declercq ${ }^{1}$ and $P$ Vandenabeele ${ }^{\star, 1}$ \\ 1 Molecular Signalling and Cell Death Unit, Department of Molecular Biomedical \\ Research, VIB and Gent University, K.L. Ledeganckstraat 35, B-9000 Ghent, \\ Belgium; \\ 2 Molecular Signalling and Inflammation Unit, Department of Molecular \\ Biomedical Research, VIB and Gent University, K.L. Ledeganckstraat 35, \\ B-9000 Ghent, Belgium \\ * Corresponding author: Peter Vandenabeele, K.L. Ledeganckstraat 35, B-9000 \\ Gent, Belgium. Tel: +32-9-264-51-31; Fax: +32-9-264-53-48; \\ E-mail: peter.vandenabeele@dmb.rug.ac.be
}

Received 4.6.02; revised 2.7.02; accepted 12.7.02

Edited by S Kumar

\begin{abstract}
Caspases are crucial for the initiation, propagation and execution of apoptosis. They normally exist as proenzymes, which can be activated through recruitment into activating complexes and by proteolytic cleavage by other caspases or proteases. Perturbation of organelles such as nuclei, endoplasmatic reticulum and mitochondria results in the activation of caspases. A number of caspases $(-2,-3,-8$ and -9$)$ were published as being localized in the intermembrane space of mitochondria. However, in three different models of apoptosis (anti-Fas-induced cell death in murine hepatocytes, Fas ligandinduced apoptosis in Jurkat cells and apoptosis induced by growth factor withdrawal in $\mathrm{Ba} / \mathrm{F} 3$ cells) we could not identify a mitochondrial location of caspases, neither under control nor under apoptotic conditions. In all three apoptotic models caspases were found in the cytosolic (caspases-2, $-3,-6,-7,-8$, -9) and nuclear subcellular fractions (caspases-2, -3). In another approach we treated isolated liver mitochondria with truncated Bid. Although tBid-dependent release of Cytochrome $c$, AIF, adenylate kinase, Smac/DIABLO and Omi/HtrA2 could be demonstrated, none of the caspases were detectable both in the supernatant and the mitochondrial fraction after treatment. Our results demonstrate that, in contrast to previous studies, no caspases- $2,-3,-8$ and -9 are associated with the mitochondrial fraction. These findings support the concept of a separate compartmentalization between proapoptotic cofactors in the mitochondria and silent precursor caspases in the cytosol.

Cell Death and Differentiation (2002) 9, 1207-1211. doi:10.1038/sj.cdd.4401101
\end{abstract}

Keywords: apoptosis; caspase; mitochondria

Abbreviations: COX, cytochrome oxidase; Ac-DEVD-amc, acetylAsp(Ome)-Glu(Ome)-Val-Asp(Ome)-aminomethylcoumarine; tBid, truncated Bid

\section{Introduction}

Apoptosis is the common physiological way of cell killing that occurs during normal development and tissue homeostasis in multicellular organisms and caspases are the key effector molecules on which presumably all apoptotic pathways converge. They are a family of evolutionarily conserved cysteine proteases that proteolyse target substrates at specific aspartate residues. ${ }^{1,2}$ To date, 13 mammalian caspases have been identified..$^{1,3-5}$ Besides their function in regulating apoptosis, some caspases, such as caspases-1, $-4,-5$ and -11 , have a function in the regulation of inflammation, ${ }^{1}$ or are associated with the differentiation of keratinocytes as is the case for caspase-14. ${ }^{6}$

The final outcome of the apoptotic proteolytic cascade is the cleavage of specific substrates, including major structural elements of the cytoplasm and nucleus, components of the DNA repair machinery and protein kinases. A long list of such caspase substrates has been reported $^{1}$ although little is known about the in vivo relevance and the functional consequence of these proteolytic events. Since these substrates are often located in different intracellular compartments, it is reasoned that caspases may reside or relocate to these compartments during apoptosis. Mitochondria have been reported to accommodate a subpopulation of procaspases-2, $-3,-8$ and $-9 .^{7-12}$ Upon apoptotic permeabilization of the mitochondrial outer membrane, mitochondrial procaspases-2, -8 and -9 would be released from the intermembrane space to the cytosol and become activated. $^{10,12}$ Recently, besides the precursor enzyme, also processed caspase-9 has been shown to be constitutively enriched in mitochondria. ${ }^{13}$ Procaspase-2 and active caspase- 2 and -3 were shown to reside at least partially in the nuclear fraction ${ }^{11,14}$ and in the Golgi complex. ${ }^{15}$ However, there is controversy in the literature concerning the mitochondrial localization of caspases. Using green fluorescent protein (GFP) as a tag, none of the caspases showed a mitochondrial localization in overexpression studies, ${ }^{16}$ although other mitochondrial proteins such as Bak or Cytochrome $c$ successfully localized in mitochondria when fused with GFP. ${ }^{16,17}$

In the present study, the possible mitochondrial localization of endogenous caspases has been studied in three different models of apoptotic cell death: anti-Fasinduced cell death in C57BL/6 hepatocytes, FasL-induced cell death in Jurkat cells and growth factor withdrawalinduced apoptosis in $\mathrm{Ba} / \mathrm{F3}$ cells. In none of these apoptotic systems we could detect precursor or active caspases in mitochondria and all caspases were clearly present and activated in the cytosol. These observations were confirmed in an in vitro apoptotic model in which highly purified liver mitochondria were treated with recombinant tBid. 


\section{Results and discussion}

Using differential and density gradient centrifugation, mitochondrial and cytosolic fractions were isolated and purity of the subcellular fractions was confirmed using immunoblot analysis for the presence of marker proteins (Cytochrome $c$ oxidase subunit IV as mitochondrial marker and $\beta$-actin as cytosolic marker (Figure 1). To investigate caspase activity, lysates from control and apoptotic mitochondrial and cytosolic fractions were incubated with the fluorogenic peptide substrate Ac-DEVD-amc. The main Ac-DEVD-amc cleavage activity is associated with the cytosolic fraction in response to the apoptotic trigger (Figure 2). Minor Ac-DEVD-amc activity is found in the mitochondrial apoptotic fraction. In order to verify these data we performed Western blotting to determine the intracellular localization of precursor and activated caspases (Figure 3). Precursor caspases-2, -3, -6, -7, -8 and -9 were only present in the cytosolic fraction of control cells. An apoptotic stimulus results in the generation of proteolytic fragments of these caspases but these are only confined to the cytosolic fraction. No caspase-2 expression could be detected in liver (Figure $3 \mathrm{~A}$ ), in agreement with previous observations. ${ }^{18}$ In none of the three apoptotic cell systems we could detect precursor or active caspases in the mitochondrial fraction. Caspase-2 and caspase-3 could also be detected in the nuclear fraction of Jurkat cells, both the proform and the activated product (Figure 4). A control for the apoptotic response of the cells studied is provided by the relocation of Cytochrome $c$ from the mitochondria to the cytosolic fraction in the three apoptotic systems (Figure 5). Upon induction of apoptosis, cytosolic Bid is cleaved to a $15 \mathrm{kDa}$ truncated protein that relocates to the mitochondria (Figure 5). Remarkably, IL-3 withdrawal from Ba/F3 cells does not result in tBid generation or Cytochrome $c$ release although caspases-2, -3, -7 and -9 were clearly processed under these apoptotic conditions (Figure 3 ). At the moment it is unclear what could be the reason for the minor caspase-independent DEVDase-activity associated with mitochondrial preparations of apoptotic Jurkat and $\mathrm{Ba} / \mathrm{F} 3$. It is conceivable that AAAproteases, an evolutionary conserved family of proteasomal ATPases located at the inner membrane, ${ }^{19}$ may be responsible for this Ac-DEVD-amc degradation as has been demonstrated for the proteasome. ${ }^{20}$

We also determined the possible release of caspases in an in vitro apoptotic system in which purified liver mitochondria were treated with recombinant tBid. ${ }^{21}$ Using this approach, we could identify Cytochrome $c$, Smac/ DIABLO, adenylate kinase-2 (AK2), Omi/HtrA2, endonuclease $G$ and apoptosis inducing factor (AIF) in the supernatant of tBid-treated mitochondria (Figure 6). However, no mitochondria-derived caspases could be identified, neither in the mitochondrial supernatant nor in the mitochondrial pellet (Figure 6). This confirms the previously mentioned absence of release of caspases from mitochondria, moreover the lack of caspases in the mitochondrial pellet even argues against a constitutive association of caspases with mitochondria, at least in the liver.

Finally, using the PSORT database (http://psort.nibb. ac.jp), no mitochondrial localization signal could be identified in any of the caspases except for procaspase-2

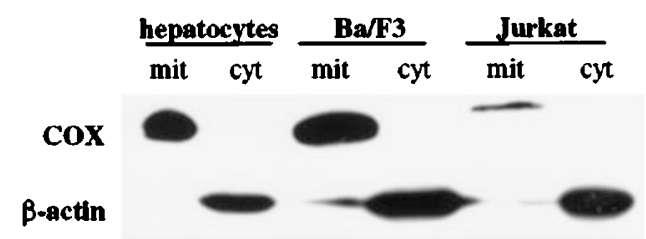

Figure 1 Isolation of mitochondrial and cytoplasmic cellular fractions. Hepatocytes, Jurkat and $\mathrm{Ba} / \mathrm{F} 3$ cells were fractionated into mitochondrial (mit) and cytosolic (cyt) fractions by differential centrifugation and Percoll gradient purification. Equal amounts of each fraction were separated by SDSPAGE and immunoblotted for detection of mitochondrial cytochrome oxidase subunit IV (COX) and cytosolic $\beta$-actin using specific antibodies

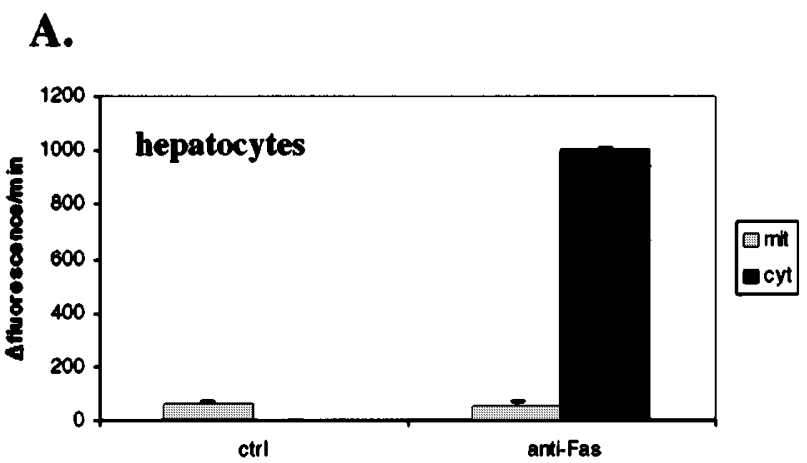

B.

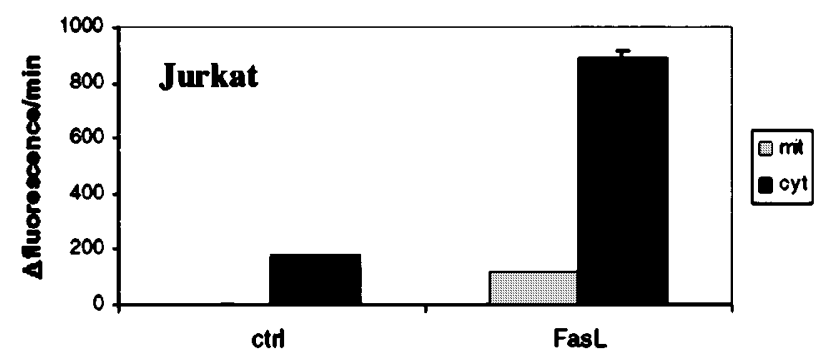

C.

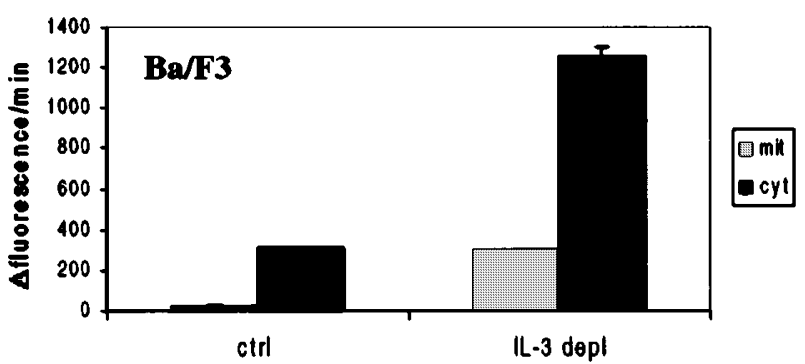

Figure 2 Detection of caspase activity in mouse hepatocytes (A), Jurkat (B) and $\mathrm{Ba} / \mathrm{F3}$ (C) cells. Mitochondria (mit) and cytosol (cyt) were isolated from control and apoptotic (anti-Fas, FasL and IL-3 deprived, respectively) cells and Ac-DEVD-amc cleavage activity was analyzed, as described in Materials and Methods. Results are representative for three independent experiments

(data not shown). Together, these data show that, at least in the three unrelated cell models we studied, the apoptotic caspase machinery is primarily confined to the cytosolic 
A.

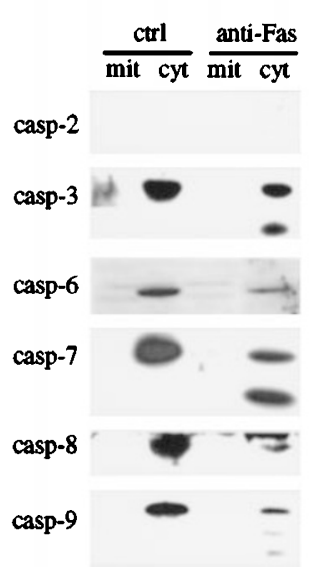

B.

C.
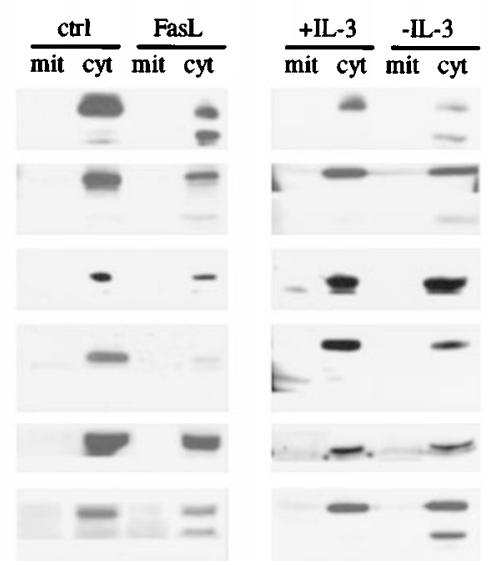

Figure 3 Subcellular localization of precursor and active caspases in mouse hepatocytes (A), Jurkat (B) and Ba/F3 (C) cells. Mitochondria (mit) and cytosol (cyt) were isolated from control and apoptotic (anti-Fas, FasL and IL-3 depleted, respectively) cells. Equal amounts of each fraction were separated by SDS-PAGE and immunoblotted for detection of caspases-2, $-3,-6,-7,-8$ and -9

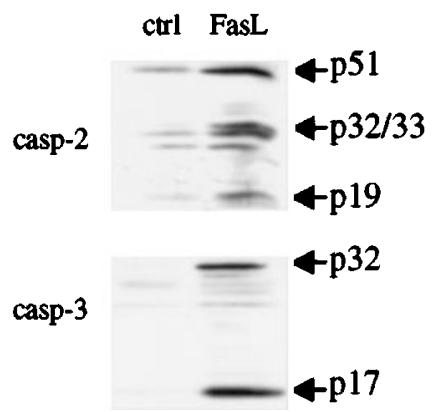

Figure 4 Identification of caspase-2 and caspase-3 in the nuclear fraction of Jurkat cells. A nuclear fraction was isolated by differential centrifugation and separated by SDS-PAGE followed by immunoblotting for detection of caspases-2 and -3

(and nuclear) compartment and that none of the caspases are present in the mitochondrial fraction neither as precursor form nor as proteolyzed fragments. However, these observations are in contrast with published data. ${ }^{7-13}$ Although some of these studies made use of the same cell types as in this report, ${ }^{8,10,11}$ a different source of commercial and non-commercial antibodies (for details on the antibodies, see Materials and Methods) were used in these localization studies. In our study, the reliability of the antisera and antibodies was confirmed by immunoreactivity on purified recombinant murine caspases and on lysates of cells transfected with murine caspase cDNA (data not shown).

Based on our observations using highly purified mitochondria, caspases are not present in the mitochondrial cell fraction of viable and apoptotic cells. These findings support the concept of a separate compartmentalization between proapoptotic cofactors in the mitochondria (Cytochrome c, AIF, Smac/DIABLO, Omi/HtrA2 and

A. B. C.

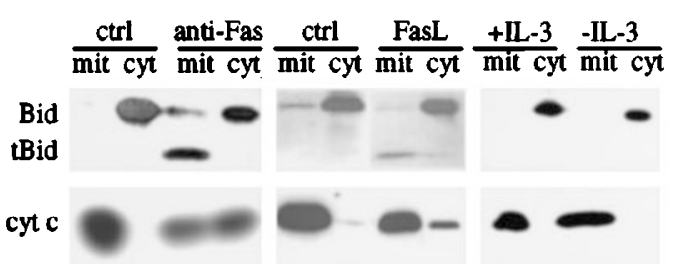

Figure 5 Subcellular relocalization of Bid and Cytochrome $c$ in hepatocytes (A), Jurkat (B) and Ba/F3 (C) cells. Mitochondria (mit) and cytosol (cyt) were isolated from control and apoptotic (anti-Fas, FasL and IL-3 depleted, respectively) cells. Equal amounts of each fraction were separated by SDSPAGE and immunoblotted for detection of Bid and Cytochrome $c$

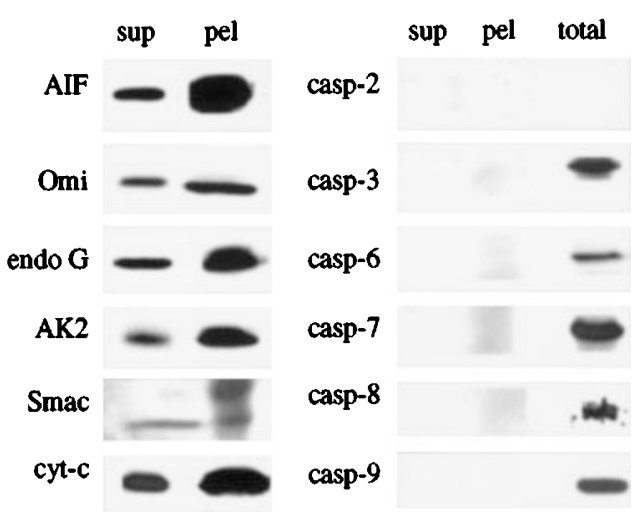

Figure 6 Identification of proteins released from mitochondria in vitro with tBid. $6.7 \mathrm{nM}$ tBid was incubated with purified liver mitochondria. Supernatants (sup) were separated from the mitochondrial pellets (pel) by centrifugation and subjected to $15 \%$ SDS-PAGE, followed by immunoblotting with antibodies against Cytochrome $c$, Smac/DIABLO, adenylate kinase-2 (AK2), endonuclease $\mathrm{G}, \mathrm{Omi} / \mathrm{HtrA} 2$, AIF and caspases-2, $-3,-6,-7,-8$ and -9 . As a control for the detection of caspases, a total liver lysate was loaded

endonuclease G) and silent precursor caspases in the cytosol.

\section{Materials and Methods}

\section{Cytokines and antibodies}

Fifteen $\mu \mathrm{g}$ monoclonal hamster anti-mouse Fas antibody Jo2 (Pharmingen, San Diego, CA, USA) was dissolved in $0.2 \mathrm{ml}$ endotoxin-free PBS and injected intravenally in C57BL/6 mice. Liver samples from J02-injected mice were excised after mice were killed when moribund and placed into ice-cold homogenization buffer $(5 \mathrm{mM}$ $\mathrm{KH}_{2} \mathrm{PO}_{4} \mathrm{pH}$ 7.4, 0.3 M sucrose, $1 \mathrm{mM}$ EGTA, $5 \mathrm{mM}$ MOPS). Soluble Flag-tagged FasL was produced in HEK293T cells and purified from its medium. Jurkat cells were killed using the FasL after crosslinking with anti-Flag antibodies (Sigma). Ba/F3 cells were induced to undergo apoptosis by overnight incubation in the absence of IL-3. Antibodies used for Western blots were anti-cytochrome oxidase subunit IV (COX) (Molecular Probes, Eugene, OR, USA), anti- $\beta$-actin (ICN, Aurora, OH, USA), anti-Cytochrome $c$ (clone $7 \mathrm{H} 8.2 \mathrm{C} 12$, Pharmingen, San Diego, CA, USA), anti-Smac/DIABLO (clone 9H10, Alexis, Switzerland), antiBid (R\&D Systems, Minneapolis, MN, USA), anti-Omi/HtrA2 (gift from Dr. Emad Alnemri, Philadelphia, PA, USA), anti-endonuclease G (gift from Dr. Adolf Ruiz-Carrillo, Barcelona, Spain), anti-AK2 (gift from Dr. 
Boris Zhivotovsky, Stockholm, Sweden), anti-AIF (gift from Dr. Patrice Petit, Paris, France), anti-caspase-2 (gift from Dr. Sharad Kumar, Adelaide, Australia), anti-human caspase-3 (BioSource, Camarillo, CA, USA), anti-human caspases-6, -7 and -9 (StressGen Biotechnologies Corp., Victoria, Canada), anti-human caspase-8 (clone 12F5, BioSource, Camarillo, CA, USA), anti-mouse caspase-8 (Santa Cruz, San Diego, CA, USA), anti-mouse caspase-9 (Cell Signaling Technology, Beverly, MA, USA). Rabbit polyclonal antibodies raised against recombinant murine caspase- $3,-6$ and $-7^{22}$ were prepared at the Centre d'Economie Rurale (Laboratoire d'Hormonologie Animale, Marloie, Belgium). HRP-coupled secondary antibodies were from Amersham (Amersham Life Science, Amersham, UK).

\section{Isolation of mitochondrial, cytosolic and nuclear fractions}

Livers of C57BL/6 mice were homogenized in cold homogenization buffer. The homogenates were cleared by centrifugation at $1800 \times g$ for $10 \mathrm{~min}$ at $4^{\circ} \mathrm{C}$ to remove intact cells and nuclei. The heavy membrane fraction (HMF) was spun down at $10000 \times g$ for $10 \mathrm{~min}$ at $4{ }^{\circ} \mathrm{C}$ and the cytosolic supernatant was further cleared by repeated centifugation at $23000 \times \mathrm{g}$ for $10 \mathrm{~min}$ at $4^{\circ} \mathrm{C}$. The HMF was subfractionated on Percoll and mitochondria were isolated as described earlier. ${ }^{21}$ Mitochondria from Jurkat and $\mathrm{Ba} / \mathrm{F} 3$ cells were isolated using a similar method in the presence of $0.1 \mathrm{mg} / \mathrm{ml}$ digitonin. For the isolation of Jurkat nuclei, cells were incubated for 30 min with $10 \mu \mathrm{M}$ cytochalasin B (Sigma, St. Louis, MO, USA) and collected by centrifugation for $5 \mathrm{~min}$ at $200 \times \mathrm{g}$. Cells were washed in cold PBS and rocked on ice for $20 \mathrm{~min}$ in NB buffer (10 mM HEPES-NaOH pH 7.5, $10 \mathrm{mM} \mathrm{KCl}, 1.5 \mathrm{mM} \mathrm{MgCl}_{2}, 1 \mathrm{mM}$ DTT, $0.1 \mathrm{mM}$ PMSF). Cells were dounced 20 times and the homogenate was brought over a double volume of a sucrose cushion in NB complete buffer (NB+30\% sucrose) and spun down at $500 \times g$ for 6 min at $4^{\circ} \mathrm{C}$. Fifty $\mu \mathrm{g}$ of the different subcellular fractions were used for Western blotting.

\section{DEVDase assay}

Caspase activity was measured by incubating $25 \mu \mathrm{g}$ cytosolic or mitochondrial cell lysate with $50 \mu \mathrm{M}$ of the fluorogenic substrate AcDEVD-AMC (Peptide Institute, Osaka, Japan) in $150 \mu$ l cell free system (CFS) buffer (10 mM HEPES-NaOH pH 7.4, 220 mM mannitol, $68 \mathrm{mM}$ sucrose, $2 \mathrm{mM} \mathrm{NaCl}, 2.5 \mathrm{mM} \mathrm{KH} \mathrm{PO}_{4}, 0.5 \mathrm{mM}$ EGTA, $2 \mathrm{mM} \mathrm{MgCl} 2$ $5 \mathrm{mM}$ pyruvate, $0.1 \mathrm{mM}$ PMSF, $1 \mathrm{mM}$ dithiothreitol). The release of fluorescent 7-amino-4-methylcoumarin was monitored for $1 \mathrm{~h}$ at $37^{\circ} \mathrm{C}$ at 2-min time intervals in a fluorometer (CytoFluor, PerSeptive Biosystems, Cambridge, MA, USA) at an excitation wavelength of $360 \mathrm{~nm}$ and an emission wavelength of $460 \mathrm{~nm}$. Data are expressed as the increase in fluorescence as a function of time ( $\Delta$ fluorescence/min).

\section{In vitro mitochondria assay}

Intact mouse liver mitochondria equivalent of $40 \mu \mathrm{g}$ protein were incubated at $37^{\circ} \mathrm{C}$ in $100 \mu \mathrm{l}$ CFS buffer for $20 \mathrm{~min}$ with $6.7 \mathrm{nM}$ recombinant $\mathrm{tBid}$, as described earlier. ${ }^{21}$ The supernatants were separated from the mitochondria by centrifugation at $20000 \times g$ for $10 \mathrm{~min}$ at $4^{\circ} \mathrm{C}$. One fifth of the supernatant was subjected to $15 \%$ SDS-PAGE followed by Western blotting with the different antibodies.

\section{Acknowledgements}

The authors thank Dr. Michel Hahne (Centro Nacional de Biotecnologia, Madrid, Spain), Dr. Sharad Kumar (Hanson Centre for Cancer Research,
Adelaide, Australia), Dr. Emad Alnemri (Kimmel Cancer Institute, Thomas Jefferson University, Philadelphia, Pennsylvania, USA), Dr. Adolf RuizCarrillo (Department of Molecular and Cell Biology, C.I.D., C.S.I.C, Barcelona, Spain), Dr. Boris Zhivotovsky (Karolinska Institute, Institute of Environmental Medicine, Stockholm, Sweden) and Dr. Patrice Petit (Institut Cochin de Génétique Moléculaire, Paris, France) for providing a plasmid expressing soluble FasL, anti-caspase 2 antibody, anti-Omi/ $\mathrm{HtrA} 2$, anti-endonuclease $\mathrm{G}$, anti-AK2 and anti-AIF, respectively. We thank Ann Meeuws and Wilma Burm for expert technical assistance and Myriam Goessens and Leen Puimege for animal care. This work was supported in part by the Interuniversitaire Attractiepolen V, the Fonds voor Wetenschappelijk Onderzoek-Vlaanderen (grant 3G.0006.01 and grant 3G.021199), an EC-RTD grant QLG1-CT-1999-00739, a RUG-cofinanciering EU project (011C0300), and a RUG-GOA project (12050502).

\section{References}

1. Earnshaw WC, Martins LM and Kaufmann SH (1999) Mammalian caspases: structure, activation, substrates, and functions during apoptosis. Annu. Rev. Biochem. 68: 383-424

2. Lamkanfi M, Declercq W, Kalai M, Saelens Xand Vandenabeele $P(2002)$ Alice in caspase land: a phylogenetic analysis of caspases from worm to man. Cell. Death Differ. 9: 358-361

3. Van de Craen M, Vandenabeele P, Declercq W, Van den Brande I, Van Loo G, Molemans F, Schotte P, Van Criekinge W, Beyaert R and Fiers W (1997) Characterization of seven murine caspase family members. FEBS Lett. 403 : $61-69$

4. Van de Craen M, Van Loo G, Pype S, Van Criekinge W, Van den brande I, Molemans F, Fiers W, Declercq W and Vandenabeele P (1998) Identification of a new caspase homologue: caspase-14. Cell. Death Differ. 5: 838-846

5. Van de Craen M, Van Loo G, Declercq W, Schotte P, Van den brande I, Mandruzzato S, van der Bruggen P, Fiers W and Vandenabeele P (1998) Molecular cloning and identification of murine caspase-8. J. Mol. Biol. 284: $1017-1026$

6. Lippens S, Kockx M, Knaapen M, Mortier L, Polakowska R, Verheyen A, Garmyn $M$, Zwijsen A, Formstecher P, Huylebroeck D, Vandenabeele P and Declercq W (2000) Epidermal differentiation does not involve the pro-apoptotic executioner caspases, but is associated with caspase-14 induction and processing. Cell. Death Differ. 7: 1218-1224

7. Mancini M, Nicholson DW, Roy S, Thornberry NA, Peterson EP, Casciola-Rosen LA and Rosen A (1998) The caspase-3 precursor has a cytosolic and mitochondrial distribution: implications for apoptotic signaling. J. Cell. Biol. 140: $1485-1495$

8. Samali A, Zhivotovsky B, Jones DP and Orrenius S (1998) Detection of procaspase-3 in cytosol and mitochondria of various tissues. FEBS Lett. 431:167169

9. Krajewski S, Krajewska M, Ellerby LM, Welsh K, Xie Z, Deveraux QL, Salvesen GS, Bredesen DE, Rosenthal RE, Fiskum G and Reed JC (1999) Release of caspase- 9 from mitochondria during neuronal apoptosis and cerebral ischemia. Proc. Natl. Acad. Sci. USA 96: 5752-5757

10. Susin SA, Lorenzo HK, Zamzami N, Marzo I, Brenner C, Larochette N, Prevost MC, Alzari PM and Kroemer G (1999) Mitochondrial release of caspase-2 and -9 during the apoptotic process. J. Exp. Med. 189: 381-394

11. Zhivotovsky B, Samali A, Gahm A and Orrenius S (1999) Caspases: their intracellular localization and translocation during apoptosis. Cell. Death Differ. 6 : 644-651

12. Qin ZH, Wang Y, Kikly KK, Sapp E, Kegel KB, Aronin Nand DiFiglia M (2001) Procaspase- 8 is predominantly localized in mitochondria and released into cytoplasm upon apoptotic stimulation. J. Biol. Chem. 276: 8079-8086

13. Costantini P, Bruey JM, Castedo M, Metivier D, Loeffler M, Susin SA, Ravagnan L, Zamzami N, Garrido C and Kroemer G (2002) Pre-processed caspase- 9 contained in mitochondria participates in apoptosis. Cell. Death Differ. 9: $82-88$

14. Colussi PA, Harvey NL and Kumar S (1998) Prodomain-dependent nuclear localization of the caspase-2 (Nedd2) precursor. A novel function for a caspase prodomain. J. Biol. Chem. 273: 24535-24542 
15. Mancini M, Machamer CE, Roy S, Nicholson DW, Thornberry NA, CasciolaRosen LA and Rosen A (2000) Caspase-2 is localized at the Golgi complex and cleaves golgin-160 during apoptosis. J. Cell. Biol. 149: 603-612

16. Shikama Y, Mami U, Miyashita T and Yamada M (2001) Comprehensive studies on subcellular localizations and cell death- inducing activities of eight GFPtagged apoptosis-related caspases. Exp. Cell. Res. 264:315-325

17. Goldstein JC, Waterhouse NJ, Juin P, Evan GI and Green DR (2000) The coordinate release of cytochrome $c$ during apoptosis is rapid, complete and kinetically invariant. Nat. Cell. Biol. 2: 156-162

18. Bergeron L, Perez Gl, Macdonald G, Shi L, Sun Y, Jurisicova A, Varmuza S, Latham KE, Flaws JA, Salter JC, Hara H, Moskowitz MA, Li E, Greenberg A, Tilly $\mathrm{JL}$ and Yuan J (1998) Defects in regulation of apoptosis in caspase-2-deficient mice. Genes Dev. 12: 1304-1314

19. Leonhard K, Guiard B, Pellecchia G, Tzagoloff A, NeupertWand LangerT (2000) Membrane protein degradation by AAA proteases in mitochondria: extraction of substrates from either membrane surface. Mol. Cell. 5: 629-638
20. Kilic M, Schafer R, Hoppe J and KagerhuberU (2002) Formation of noncanonica high molecular weight caspase- 3 and -6 complexes and activation of caspase- 12 during serum starvation induced apoptosis in AKR-2B mouse fibroblasts. Cell. Death Differ. 9: 125-137

21. Van Loo G, Demol H, van Gurp M, Hoorelbeke B, Schotte P, Beyaert R, Zhivotovsky B, GevaertK, Declercq W, Vandekerckhove J and Vandenabeele $P$ (2002) A matrix-assisted laser desorption ionization post-source decay (MALDIPSD) analysis of proteins released from isolated liver mitochondria treated with recombinant truncated Bid. Cell. Death Differ. 9: 301-308

22. Van de Craen M, Declercq W, Van den brande I, Fiers W and Vandenabeele $P$ (1999) The proteolytic procaspase activation network: an in vitro analysis. Cell Death Differ. 6: 1117-1124 